\title{
Splenectomy proportions are still high in low-grade traumatic splenic injury
}

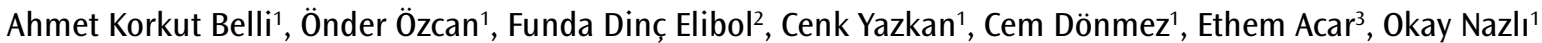

Cite this paper as:

Belli AK, Özan 0̈, Dinç Elibol

F, Yazkan C, Dönmez C, Acar

E, Nazlı 0. Splenectomy

proportions are still high in

low-grade traumatic splenic

injury. Turk J Surg 2018; 34:

106-110.

'Departmant of General Surgery, Muğla Sitkı Koçman University School of Medicine, Muğla, Turkey

2Department of Radiology, Muğla Sıtkı Koçman University School of Medicine, Muğla, Turkey

${ }^{3}$ Department of Emergency Medicine, Muğla Sıtkı Koçman University School of Medicine, Muğla, Turkey

This study was presented at the "20th National Surgical Congress", 13-17 April 2016, Antalya, Turkey.

\section{Corresponding Author}

Ahmet Korkut Belli e-mail: hmetbelli@gmail.com

Received: 25.10 .2016 Accepted: 18.05.2017

Available Online Date: 30.04 .2018

CCopyright 2018 by Turkish Surgical Association
Objective: The spleen is the most vulnerable organ in blunt abdominal trauma. Spleen-preserving treatments are non-operative management with or without splenic angioembolization, partial splenectomy, and splenorrhaphy. The aim of the present study was to determine the rate of SPTs and to evaluate the usefulness of Injury Severity Score after traumatic splenic injury.

Material and Methods: We searched our institution's database between May 2012 and December 2015. Patients' clinicopathological features, surgeon's title, type of treatment, admission and discharge dates, duration of surgery, intensive care unit requirement, and Glasgow Coma Scale were recorded.

Results: The mean age of patients was $33.36 \pm 11.58$ years. Of the 33 patients, $26(78.8 \%)$ were males, and 7 (21.2\%) were females. Thirty (90.9\%) had total splenectomy (TS), and $3(9.1 \%)$ had spleen preserving treatment (2 Nonoperative management and 1 partial splenectomy). No fatal hemorrhage developed after nonoperative management. Exitus rates were $5 / 30(15.1 \%)$ and $0 / 3$ in the total splenectomy and spleen preserving treatment groups, respectively. Of the 18 hemodynamically stable patients, only $2(11.1 \%)$ had spleen preserving treatment. Of the 19 patients with grade I-III splenic injury, only $3(15.8 \%)$ had spleen preserving treatment. For academic and non-academic surgeons, spleen preserving treatment rates were $3 / 11(27.3 \%)$ and $0 / 22(0 \%)$, respectively $(p<0.05)$. Injury severity score and mean arterial pressure, number of transfusions, control hematocrit, and GCS had statistically significant relationships.

Conclusions: Spleen preserving treatment proportions were low after traumatic splenic injury. Following trauma, guidelines will not only improve spleen preservation rates but also improve the overall health status of the patients and it will also prevent complications of splenectomy.

Keywords: Splenectomy, surgery, emergency, spleen-preserving treatment, trauma

\section{INTRODUCTION}

The spleen is the most vulnerable organ in blunt abdominal trauma owing to its location and vascularization. Splenectomy is the only treatment for all splenic injuries before 1960 (1). However, spleenpreserving treatments (SPTs) including non-operative management (NOM) with or without splenic angioembolization (SAE), partial splenectomy, and splenorrhaphy have been gradually implemented in time.

The spleen has several critical functions according to its histological parts including the red pulp or white pulp. In the red pulp, it filters and removes senescent erythrocytes in the circulation and recycles iron for the production of new erythrocytes. In the white pulp, it functions as a secondary lymphoid organ and generates both humoral and cellular immune responses. Moreover, $30 \%$ of the total thrombocytes are sequestered in the spleen. After splenectomy, cytoplasmic inclusions, including Heinz or Howell-Jolly bodies, occur in the erythrocytes, and the number of granulocytes and thrombocytes start to increase. Complications of splenectomy include atelectasis, pancreatitis, postoperative hemorrhage, thromboembolism, portal vein thrombosis, and fulminant bacteremia (2).

The aim of the present study was to determine the rate of SPTs in our institution, which factors are effective on the treatment choice, and to evaluate the usefulness of Injury Severity Score (ISS) after traumatic splenic injury.

\section{MATERIAL AND METHODS}

The study was performed in accordance with the Declaration of Helsinki.

\section{Patient selection}

We searched our institution's database between May 2012 and December 2015 to identify patients who had total or partial splenectomy due to trauma. Data were collected from the institution's archive. Patients who had splenectomy due to non-traumatic causes were excluded from the study. 


\section{Data collection}

We started to search our database from May 2012 because our electronic health record system was set up to the current database system. Patient name, gender, date of surgery, surgeon's title, academic or non-academic, type of treatment (NOM, partial splenectomy, or total splenectomy (TS)), admission and discharge date, duration of surgery, referral status from outside hospitals, intensive care unit (ICU) requirement, Glasgow Coma Scale (GCS), number of transfusions such as erythrocyte suspension (ES) and fresh frozen plasma (FFP), and injuries other than the spleen were recorded in an electronic database system.

Transfusions given between the induction of anesthesia and finalization of surgical operation were called perioperative transfusions, and the number of transfusions given during hospital stay was called total number of transfusions.

Table 1. Clinical and pathological features of the patients according to treatment choice

\begin{tabular}{|c|c|c|}
\hline & $\begin{array}{c}\text { Total } \\
\text { splenectomy } \\
(n=30) \\
\text { Mean } \pm \text { SD or } \\
\text { median } \\
(\text { min-max })\end{array}$ & $\begin{array}{c}\text { Spleen- } \\
\text { preserving } \\
\text { treatment }(n=3) \\
\text { (NOM: } 2 \text {, partial } \\
\text { splenectomy: } 1) \\
\text { Mean } \pm \text { SD or } \\
\text { median } \\
\text { (min-max) }\end{array}$ \\
\hline Mean age (year) & $33.9 \pm 11.6$ & $28 \pm 10.8$ \\
\hline \multicolumn{3}{|l|}{ Gender } \\
\hline Male & $24(80 \%)$ & $2(66.7 \%)$ \\
\hline Female & $6(20 \%)$ & $1(33.3 \%)$ \\
\hline \multicolumn{3}{|l|}{ Surgeon's title } \\
\hline Non-academic surgeon & $22(73.3 \%)$ & $0(0 \%)$ \\
\hline Academic surgeon & $8(26.6 \%)$ & $3(100 \%)$ \\
\hline
\end{tabular}

Hemodynamic status

$\begin{array}{lll}\text { Stable } & 16(53.3 \%) & 2(66.7 \%)^{*} \\ \text { Unstable } & 14(46.7 \%) & 1(33.3 \%)^{*}\end{array}$

$\begin{array}{lcc}\text { Grades of splenic injury } & \\ \text { I-III } & 19(65.5 \%) & 3(100 \%) \\ \text { IV-V } & 10(34.5 \%) & 0(0 \%)\end{array}$

ICU status

$\begin{array}{lcc}\text { Required } & 15(50 \%) & 1(33.3 \%) \\ \text { Not required } & 15(50 \%) & 2(66.7 \%) \\ \text { Median ISS } & 21(4-75) & 17(9-22) \\ \text { Median GCS } & 15(3-15) & 15(14-15) \\ \text { Median duration of surgery (min) } & 100(50-165) & 40(40-40) \\ \text { Mean hospital stay (days) } & 7(0-31) & 6(5-7) \\ \text { Median total ES } & 3.36(0-18) & 1(0-2) \\ \text { Median perioperative ES } & 1.27(0-10) & 0(0-0) \\ \text { Mean total FFP } & 1.77 \pm 1.87 & 1 \pm 1.73 \\ \text { Median perioperative FFP } & 0.46(0-4) & 0(0-0)\end{array}$

*Hemodynamically stable patients were treated with NOM, and unstable patients were treated with partial splenectomy SD: standard deviation; ICU: intensive care unit; ES: erythrocyte suspension; FFP: fresh frozen plasma; ISS: Injury Severity Score; GCS: Glasgow Coma Scale; NOM: non-operative management
We defined an academic surgeon according to the following criteria: a surgeon who works in a teaching hospital and giving lectures to medical students and/or residents and who supposedly follow current treatment guidelines. On the other hand, a non-academic surgeon was defined as a general surgeon who has no teaching responsibility.

\section{Calculation of ISS}

We searched all injuries other than the spleen from the patient files and determined the organ injury scales (Abbreviated Injury Scale scores) and ISS calculated for each patient according to Baker et al. (3).

\section{Evaluation of hemodynamic stability}

We calculated mean arterial pressures (MAPs) from the initial and control systolic and diastolic blood pressures (SBP and $\mathrm{DBP}$ ) using the following formula: $\mathrm{MAP}=1 / 3 \times \mathrm{SBP}+2 / 3 \mathrm{DBP}$ ). The control BP was measured after administering 500 to 1500 cc intravenous crystalloid infusion. We accepted operating room $\mathrm{BP}$ if there was no control $\mathrm{BP}$ in the emergency setting. Difference between the initial and control hemoglobin $(\mathrm{Hb})$ and hematocrit (Hct) levels was calculated using the following formula: ((initial $\mathrm{Hb}-$ control $\mathrm{Hb}$ )/initial $\mathrm{Hb} \times 100$ ) and ((initial Hct-control Hct)/initial Hct $\times 100)$. Hemodynamic instability criteria were as follows: (1) a MAP level $<65 \mathrm{~mm} \mathrm{Hg}$ in the control BP and (2) an $\mathrm{Hb}$ or Hct difference percentage $>20$.

\section{Grading of splenic injury}

Our radiologist re-evaluated all patients' abdominal computed tomography (CT) scans according to the American Association for the Surgery of Trauma (AAST) grading system. Of the 33 patients, 29 had appropriate CT images for AAST grading. We also checked the pathology reports for the remaining patients for grading. One patient had no grading data available.

\section{Our staff}

Two professors, three assistant professors, and eight general surgeons were working in the department of general surgery while conducting this research.

\section{Statistical analysis}

We performed all statistical analysis after obtaining consultation from the Department of Biostatistics. Since SPTs are gold standards of treatment for grade I-II and recommended for grade III splenic injury and TS is recommended for grade IV-V injury according to the trauma guidelines, we categorized patients into grade I-III and grade IV-V to perform a better statistical analysis for the grades. We compared two categorical data with either Pearson chi-square or Fisher's exact test. To compare a categorical and a scale data, we used independent samples t or Mann-Whitney $\mathrm{U}$ tests. For the scale data, we used Pearson correlation test.

\section{RESULTS}

Of the 33 patients who had traumatic splenic injury, 26 (78.8\%) were males, and 7 (21.2\%) were females. The mean age of patients was $33.36 \pm 11.58$ years (ranging from 7 to 59 years). Of the 33 patients, $30(90.9 \%)$ had TS, and $3(9.1 \%)$ had SPT (2 NOM and 1 partial splenectomy). No fatal hemorrhage developed during the follow-up of the patients treated with NOM. Exitus rates were $5 / 30(15.1 \%)$ and $0 / 3$ in the TS and SPT, respectively. Eighteen (54.5\%) were hemodynamically stable, and $15(45.5 \%)$ were unstable. Of the 18 hemodynamically 
Belli et al.

Splenectomy proportions in traumatic splenic injury Table 2. Clinical features of the patients with splenic injury
according to academic vs non-academic surgeons

\begin{tabular}{|lccc|}
$\begin{array}{l}\text { Clinical } \\
\text { features of } \\
\text { the patients }\end{array}$ & $\begin{array}{c}\text { Academic } \\
\text { surgeon } \\
(\mathbf{n}=11)\end{array}$ & $\begin{array}{c}\text { Non- } \\
\text { academic } \\
\text { surgeon } \\
(\mathbf{n = 2 2})\end{array}$ & $\mathbf{p}$ \\
\hline Mean age (year) & $30.6 \pm 12.6$ & $34.7 \pm 11.08$ & 0.77 \\
Gender & & & \\
Male & $8(72.7 \%)$ & $18(81.8 \%)$ & 0.66 \\
Female & $3(27.3 \%)$ & $4(18.2 \%)$ & \\
Grades of splenic injury & & & \\
I-III & $8(72.7 \%)$ & $14(63.6 \%)$ & 1 \\
IV-V & $3(27.3 \%)$ & $7(31.8 \%)$ & \\
\hline
\end{tabular}

Hemodynamic status

\begin{tabular}{llcc} 
Stable & $5(54.5 \%)$ & $13(59.1 \%)^{*}$ & 0.48 \\
Unstable & $6(45.5 \%)$ & $9(40.9 \%)^{*}$ & \\
\hline Median ISS & $22(4-75)$ & $17(4-75)$ & 0.3 \\
\hline
\end{tabular}

\section{ICU status}

\begin{tabular}{|lccc|} 
Required & $6(54.5 \%)$ & $10(47.6 \%)$ & 0.71 \\
Not required & $5(45.5 \%)$ & $11(52.4 \%)$ & \\
\hline Median GCS & $14(3-15)$ & $15(12-15)$ & 0.03 \\
\hline Median duration & $90(40-120)$ & $100(50-165)$ & 0.68 \\
\hline
\end{tabular}

of surgery (min)

\begin{tabular}{|c|c|c|c|}
\hline $\begin{array}{l}\text { Median duration } \\
\text { of hospital stay } \\
\text { (days) }\end{array}$ & $5(0-27)$ & $7(0-31)$ & 0.32 \\
\hline $\begin{array}{l}\text { Median no. } \\
\text { of consultations }\end{array}$ & $4.5(1-7)$ & $3(1-7)$ & 0.23 \\
\hline Median total ES (packs) & $3(0-18)$ & $3(0-9)$ & 0.89 \\
\hline $\begin{array}{l}\text { Median perioperative } \\
\text { ES (packs) }\end{array}$ & $2(0-10)$ & $1(0-5)$ & 0.62 \\
\hline Mean total FFP (packs) & $2 \pm 1.55$ & $1.55 \pm 1.99$ & 0.51 \\
\hline $\begin{array}{l}\text { Median perioperative } \\
\text { FFP (packs) }\end{array}$ & $0(0-4)$ & $0(0-3)$ & 0.78 \\
\hline \multicolumn{4}{|l|}{ Treatment type } \\
\hline SPT & $3(27.3 \%)$ & $0(0 \%)$ & 0.03 \\
\hline Total splenectomy & $8(72.7 \%)$ & $22(100 \%)$ & \\
\hline
\end{tabular}

ISS: Injury Severity Score; ICU: intensive care unit; GCS: Glasgow Coma Scale; ES: erythrocyte suspension; FFP: fresh frozen plasma; SPT: spleen-preserving treatment

stable patients, only $2(11.1 \%)$ had SPT. Thirty-two out of the 33 patients' information were available for grading; 6 (18.8\%) had grade I, 2 (6.3\%) had grade II, 14 (43.8\%) had grade III, 3 $(9.4 \%)$ had grade IV, and 7 (21.9\%) had grade V splenic injury. Of the 22 patients with grade I-III splenic injury, only 3 (15.8\%) had SPT. Of the 18 hemodynamically stable patients, only 2 (11.1\%) had SPT. The mean ISSs were $15.28 \pm 8.28$ and 39.33 \pm 28.1 ( $p>0.05$ ) for hemodynamically stable and unstable patients, respectively. Sixteen (48.5\%) patients needed ICU postoperatively. Regarding the surgeon's title, there were three academic vs six non-academic surgeons (Tables 1-3).

Patients' clinical features according to academic and nonacademic surgeons were the following: mean ages were
Table 3. Clinical features of the patients according to hemodynamic status

\begin{tabular}{|lccc|}
\hline & Stable & Unstable & p \\
\hline Mean age (year) & $33.6 \pm 10.4$ & $33.06 \pm 13.2$ & 0.89 \\
\hline Mean initial MAP & $77.25 \pm 12.2$ & $72.22 \pm 15.1$ & 0.31 \\
\hline $\begin{array}{l}\text { Median initial } \\
\text { fluid replacement }\end{array}$ & 1000 & 1000 & 0.63 \\
\hline Mean control MAP & $85.38 \pm 15.37$ & $71 \pm 19.4$ & 0.04 \\
\hline Mean Hct change \% & $-0.44 \pm 26.3$ & $27.4 \pm 15.2$ & 0.02 \\
\hline $\begin{array}{l}\text { Median total ES (packs) } \\
\text { Mean total FFP (packs) }\end{array}$ & $2(0-9)$ & $4(0-18)$ & 0.08 \\
\hline $\begin{array}{l}\text { Median perioperative } \\
\text { ES (packs) }\end{array}$ & $1.16 \pm 1.65$ & $2.3 \pm 1.9$ & 0.07 \\
\hline $\begin{array}{l}\text { Median perioperative } \\
\text { FFP (packs) }\end{array}$ & $0(0-3)$ & $1(0-10)$ & 0.91 \\
\hline $\begin{array}{l}\text { Median duration } \\
\text { of surgery (min) }\end{array}$ & $90(50-165)$ & $120(40-120)$ & 0.5 \\
\hline $\begin{array}{l}\text { Mean ISS } \\
\text { Gusp: }\end{array}$ & $15.28 \pm 8.28$ & $39.33 \pm 28.1$ & 0.08 \\
\hline \begin{tabular}{l} 
Mean hospital stay (days) \\
\hline Median GCS
\end{tabular} & $9.94 \pm 7.9$ & $5.86 \pm 5.08$ & 0.96 \\
\hline
\end{tabular}

Table 4. Statistically significant correlations between ISS and other clinical factors

$\begin{array}{llcc}\text { Variables } & & \mathbf{p} & \begin{array}{c}\text { Correlation } \\ \text { coefficient }(\mathbf{r})\end{array} \\ \text { ISS } & \text { Initial SBP } & 0.007 & -0.46 \\ & \text { Control SBP } & 0.02 & -0.51 \\ & \text { Initial MAP } & 0.02 & -0.4 \\ \text { Control MAP } & 0.03 & -0.37 \\ & \text { Control Hct } & 0.04 & -0.37 \\ & \text { Perioperative ES } & 0.04 & 0.36 \\ & \text { Perioperative FFP } & 0.04 & 0.36 \\ & \text { Total FFP } & 0.007 & 0.46 \\ \text { GCS } & 0.001 & -0.57\end{array}$

SBP: systolic blood pressure; MAP: mean arterial pressure; Hct: hematocrit; ES: erythrocyte suspension; FFP: fresh frozen plasma; ISS: Injury Severity Score; GCS: Glasgow Coma Scale

$30.6 \pm 12.6$ years and $34.7 \pm 11.08$ years $(p>0.05)$, grade I-III/IV-V proportions were $8 / 3$ and $14 / 7$ ( $p>0.05)$, hemodynamic stability/instability proportions were $5 / 6$ and $13 / 9$ ( $p>0.05$ ), ICU requirements were $6(54.5 \%)$ and $10(47.6 \%)(p>0.05)$, median ISSs were 22 (4-75) and 17 (4-75) ( $p>0.05)$, median GCSs were $14(3-15)$ and $15(12-15)(p<0.05)$, and SPTs were $3(27.3 \%)$ and $0(0 \%)(p<0.05)$, respectively (Table 2$)$.

ISS was negatively correlated with initial SBP (p: 0.007, r: -0.46), control SBP (p: 0.02, r: -0.51), initial MAP (p: 0.02, r: -0.4), control MAP (p: 0.03, r: -0.37$)$, control Hct (p: 0.04, r: -0.37 ), and GCS (p: $0.001, r:-0.57)$; positively correlated with perioperative ES (p: 0.04, r: 0.36) and perioperative FFP (p: 0.04, r: 0.36) (Table 4). 


\section{DISCUSSION}

Non-operative treatments with or without SAE, partial splenectomy, and splenorrhaphy are considered as SPTs. The advantages of spleen preservation are maintaining splenic function, avoiding post-splenectomy sepsis, and preventing thrombosis or laparotomy complications (4). Non-operative treatment was first used in pediatric splenic trauma in 1968 and is currently the gold standard of treatment in grade I-II splenic injury $(1,4,5)$. The most important complication of NOM is delayed fatal hemorrhage; however, no delayed hemorrhage developed during the follow-up of our NOM patients who had grade III splenic injuries (6).

Jeremitsky et al. (7) investigated NOM success rates in 15.732 patients presenting with blunt splenic injury and reported that the overall splenic salvage rate is $81 \%$, and the NOM success rate is $95 \%$ after $5 \mathrm{~h}$ of arrival. Dehli et al. (8) evaluated the success rate of SAE with NOM and reported that this combination decreases the rate of splenectomy. Nevertheless, Olthoff et al. (9) corrected the confounding factors using a propensity score while evaluating the success rate of SAE and found no significant difference between the patients who were observed and who had SAE.

The mortality rate of NOM for patients with grade I-II injury was found to be $0 \%$. For grade III injuries, the mortality rate of NOM was found to be closer to operative managements. For grade IV-V patients, the NOM mortality rate was found to be higher than operative management $(6,10,11)$. Since there was no contrast extravasation in abdominal CT images in grade III splenic injury and it is recommended by the guidelines, we tried to perform NOM in this group of patients. Thus, we categorized patients into grades I-III and IV-V, as mild and severe splenic injuries, to perform a better statistical analysis. In total, 3 patients with grade III splenic injury were treated with SPTs, with 2 NOM and 1 partial splenectomy, and all of them recovered with no complications in our study.

Several studies in Turkey reported spleen preservation rates ranging from $11 \%$ to $66 \%$ after a traumatic splenic injury (1215). Koksal et al. (11) reported that the NOM rate for traumatic splenic injury is $12.2 \%$ between the years 1994 and 1997 in their institution and increases to $76.9 \%$ between the years 1998 and 2000 with a $100 \%$ NOM success rate. Arikan et al. (13) reported that traumatic splenic injuries are treated $89 \%$ with TS, 7\% with splenorrhaphy, and $4 \%$ with partial splenectomy between the years 1992 and 1998 in their institution. Moreover, Yanar et al. (14) investigated the effective factors on NOM success rate and stated that the initial lactate level, solid viscus score, transfusion requirement, fluid replacement, and Hct change are significant factors. Furthermore, Topaloglu et al. (15) reported that the ratio of complications, including wound infection, lung infection, pneumothorax, urinary infection, and re-laparotomy, after a traumatic splenic injury is $18.06 \%$.

Factors that influence the treatment choice after traumatic splenic injury have not been identified in the literature. One study from Olthof et al. (16) reported that SAE and surgery rates vary in five different academic hospitals; however, no effective factor was identified in the treatment choice. We found in our study that academic surgeons performed more
SPT than non-academic surgeons even if the proportions were still low, $27 \%$ vs $0 \%$. This relationship may be due to the fact that academic surgeons follow trauma guidelines better, take more surgical risks in their hospital settings, or are younger surgeons than non-academic surgeons. Academic surgeons' responsibility for resident and medical student training may lead them to perform contemporary procedures.

University hospitals, training and research hospitals, community hospitals, private hospitals, newly established affiliated hospitals, and union of university and community hospitals are types of hospitals in Turkey. Some institutions have been leading in modern treatment methods in Turkey such as university and training and research hospitals. However, to our knowledge, there is no study that compared the NOM rates for splenic injuries among these institutions, and there may be different rates of NOM among these institutions. Nevertheless, SPT proportion for patients who had low-grade splenic injury or patients who were hemodynamically stable is still very low and needs to be improved to be consistent with trauma guidelines. Moreover, our study is a unique study that investigated the factors affecting SPTs after traumatic splenic injury and may give rise to further investigations in this topic.

Furthermore, we also investigated the importance of ISS in traumatic splenic injury and found that it was significantly correlated with the initial and control SBPs and MAPs, number perioperative ES and FFP, total FFP, control Hct, and GCS. Therefore, it appears that calculating ISS for patients with trauma in an emergency room may assist physicians to determine the prognosis of the patient, required number of transfusions, or even the need for ICU requirement.

\section{CONCLUSION}

We found in our study that SPT proportions were still very low in traumatic splenic injury. This management is inconsistent with trauma guidelines. Surgeons should be more careful about following trauma guidelines to improve the overall health status of the patients and to prevent complications of splenectomy.

Ethics Committee Approval: The authors declared that the research was conducted according to the principles of the World Medical Association Declaration of Helsinki "Ethical Principles for Medical Research Involving Human Subjects.

Informed Consent: Written informed consent was obtained from patient who participated in this study.

Peer-review: Externally peer-reviewed.

Author Contributions: Concept - A.K.B.; Design - A.K.B.; Supervision - A.K.B.; Resource - A.K.B., Ö.Ö., C.D., O.N.; Materials - A.K.B., Ö.Ö., C.D., O.N.; Data Collection and/or Processing - A.K.B., F.D.E., C.Y., E.A.; Analysis and/or Interpretation - A.K.B.; Literature Search - A.K.B, C.Y.; Writing Manuscript - A.K.B.; Critical Reviews - A.K.B., Ö.Ö., O.N.

Conflict of Interest: The authors have no conflicts of interest to declare.

Financial Disclosure: The authors declared that this study has received no financial support. 


\section{REFERENCES}

1. Cirocchi R, Boselli C, Corsi A, Farinella E, Listorti C, Trastulli S, et al. Is non-operative management safe and effective for all splenic blunt trauma? A systematic review. Crit Care 2013; 17: R185. [CrossRef]

2. Fraker DL. Spleen. In: Doherty GM editor. Current diagnosis and treatment. 13th ed. New York: McGraw-Hill; 2010. p. 597-614.

3. Baker SP, O'Neill B, Haddon W Jr, Long WB. The injury severity score: a method for describing patients with multiple injuries and evaluating emergency care. JTrauma 1974; 14:187-196. [CrossRef]

4. Rosati C, Ata A, Siskin GP, Megna D, Bonville DJ, Stain SC. Management of splenic trauma: a single institution's 8-year experience. Am J Surg 2015; 209: 308-314. [CrossRef]

5. Upadhyaya P. Conservative management of splenic trauma: history and current trends. Pediatr Surg Int 2003; 19: 617-627. [CrossRef]

6. Velmahos GC, Zacharias N, Emhoff TA, Feeney JM, Hurst JM, Crookes BA, et al. Management of the most severely injured spleen: a multicenter study of the Research Consortium of New England Centers for Trauma (ReCONECT). Arch Surg 2010; 145: 456-460. [CrossRef]

7. Jeremitsky E, Smith RS, Ong AW. Starting the clock: defining nonoperative management of blunt splenic injury by time. Am J Surg 2013; 205: 298-301. [CrossRef]

8. Dehli T, Bågenholm A, Trasti NC, Monsen SA, Bartnes K. The treatment of spleen injuries: a retrospective study. Scand J Trauma Resusc Emerg Med 2015; 23: 85. [CrossRef]
9. Olthof DC, Joosse P, Bossuyt PM, de Rooij PP, Leenen LP, Wendt $\mathrm{KW}$, et al. Observation Versus Embolization in Patients with Blunt Splenic Injury After Trauma: A Propensity Score Analysis. World J Surg 2015; 40: 1264-1271. [CrossRef]

10. Duchesne JC, Simmons JD, Schmieg RE Jr, McSwain NE Jr, Bellows CF. Proximal splenic angioembolization does not improve outcomes in treating blunt splenic injuries compared with splenectomy: a cohort analysis. J Trauma 2008; 65: 1346-1351. [CrossRef]

11. Jim J, Leonardi MJ, Cryer HG, Hiatt JR, Shew S, Cohen M, et al. Management of high-grade splenic injury in children. Am Surg 2008; 74: 988-992.

12. Koksal N, Uzun MA, Muftuoğlu T. Hemodynamic stability is the most important factor in nonoperative management of blunt splenic trauma. Ulus Travma Derg 2000; 6: 275-280.

13. Arikan $S$, Yücel AF, Adas $G$, Culcu $D$, Gulen $M$, Arinc O. Splenic trauma and treatments. Haseki Educational and Research Hospital Surgical Department survey of the feasibility of surgery for splenic trauma. Ulus Travma Derg 2001; 7: 250-253.

14. Yanar H, Ertekin C, Taviloglu K, Kabay B, Bakkaloglu H, Guloglu R. Nonoperative treatment of multiple intra-abdominal solid organ injury after blunt abdominal trauma. J Trauma 2008; 64: 943-948. [CrossRef]

15. Topaloğlu U, Yilmazcan A, Unalmişer S. Protective procedures following splenic rupture. Surg Today 1999; 29: 23-27. [CrossRef]

16. Olthof DC, Luitse JS, de Rooij PP, Leenen LP, Wendt KW, Bloemers $\mathrm{FW}$, et al. Variation in treatment of blunt splenic injury in Dutch academic trauma centers. J Surg Res 2015; 194: 233-238.[CrossRef] 